Ensino, Saúde e Ambiente - V10 (1), pp. 27-54, Abril. 2017

\title{
UMA COMPREENSÃO SOBRE O ENSINO DA COSMOLOGIA NA PERSPECTIVA DE PROFESSORES E INVESTIGADORES
}

\section{AN UNDERSTANDING OF THE TEACHING OF COSMOLOGY FROM THE PERSPECTIVE OF TEACHERS AND RESEARCHERS}

\author{
Milene Rodrigues Martins ${ }^{1}$, Marcos Cesar Danhoni Neves ${ }^{1}$ \\ ${ }^{1}$ Universidade Estadual de Maringá/ Programa de Pós-graduação em Educação para a Ciência e a \\ Matemática, milene.rm1@gmail.com \\ ${ }^{2}$ Universidade Estadual de Maringá/ Programa de Pós-graduação em Educação para a Ciência e a \\ Matemática, macedane@yahoo.com.br
}

\begin{abstract}
RESUMO
As pesquisas voltadas para o ensino da Cosmologia ainda estão a caminhar a passos lentos, uma vez que, há poucos estudos desenvolvidos com esse enfoque. Nesta perspectiva, considerando as inquietudes pertinentes à origem do universo, este trabalho tem por objetivo investigar o discurso de seis professores e pesquisadores de duas instituições de ensino superior, sendo uma de âmbito nacional e outra internacional. Para tanto, este trabalho terá como foco de estudo três evidências empíricas complexas que não permitem apenas uma interpretação: desvios para o vermelho (redshifts); radiação cósmica de fundo (CBR) e quasares. A obtenção dos dados se deu por meio de entrevistas filmadas, para posterior transcrição e interpretação das mesmas. A análise dos dados foi embasada nos pressupostos teóricos e metodológicos da pesquisa fenomenológica. Ao término das análises concluiu-se que a importância do ensino da Cosmologia ainda não é consenso entre os professores e pesquisadores, bem como a metodologia a ser adotada. Em relação à abordagem de modelos cosmológicos alternativos ao modelo padrão, os sujeitos de pesquisa, também não estão em consonância. Ademais, parece ser unanimidade entre os sujeitos de pesquisa a concepção de que em relação ao universo há muito a ser descoberto, investigado e estudado, uma vez que, se conhece apenas uma porção ínfima do mesmo. Em relação às três evidências empíricas (redshifts, quasares e radiação cósmica de fundo), os sujeitos de pesquisa que versaram sobre as mesmas, apresentaram somente as interpretações que corroboram para a solidificação da teoria do big bang (estrondão).
\end{abstract}

Palavras-chave: Big Bang; Estado Estacionário; Ensino da Cosmologia Contemporânea.

\begin{abstract}
The research focused on the teaching of Cosmology is still walking in slow steps, since there are few studies conducted with this focus. From this perspective, considering relevant questions on the origin of the universe, this paper aims to investigate the discourse of six professors and researchers from both institutions of higher education with national and international scope. Therefore, this work will be focused on three complex empirical evidences that do not allow a single interpretation: redshifts, cosmic microwave background radiation (CMB), and Quasars. The data was obtained through interviews shot for later transcription and interpretation. The data analysis was based on theoretical and methodological assumptions of phenomenological research. Upon the
\end{abstract}


end of the analysis, it is concluded that the importance of Cosmology teaching does not present any agreement among teachers and researchers, as well as the methodology to be adopted. Compared with the approach of alternative cosmological models to the standard model, the research subjects are also not in concordance. Moreover, it seems to be unanimity among the research subjects the view that in relation to the universe there is much more to be discovered, investigated and studied, since it is known only a tiny portion of the universe. Regarding the three empirical evidences (redshifts, quasars and the cosmic microwave background), the subjects who studied and discussed these topics represented only the interpretations which support the big bang theory.

Key words: Big Bang; Stationary state; Teaching Contemporary Cosmology.

\section{INTRODUÇÃO}

A Cosmologia é um dos mais antigos empreendimentos intelectuais da humanidade. É igualmente um dos mais fascinantes. Não só do ponto de vista científico, mas também do ponto de vista filosófico, histórico e epistemológico. Ela configura-se como uma ciência integradora, onde busca empregar o saber de outras áreas do conhecimento, como por exemplo, a física, a matemática, a astronomia, no sentido de montar um cenário universal.

O homem, enquanto parte integrante do objeto que se propõe a estudar - o universo, não ocupa uma posição desejável para estabelecer e compreender as leis que governam a natureza. Surge dessa forma, uma pluralidade de teorias que visam fornecer explicações satisfatórias para os dados observacionais e/ou experimentais de porções ínfimas do universo, a que se tem acesso.

O ensino da Cosmologia, contudo, comumente não recebe a devida atenção, uma vez que, há poucas pesquisas voltadas para essa área. Ao realizar um breve levantamento das teses e dissertações defendidas no Brasil com esse enfoque, junto ao Banco de Teses e Dissertações sobre Educação em Astronomia ${ }^{1}$, foram encontradas apenas cinco dissertações, publicadas entre 2006 e 2011. São elas: Noções de Cosmologia no Ensino Médio: O paradigma criacionista do big bang e a inibição de teorias rivais (2006); A Cosmologia moderna à luz dos elementos da epistemologia de Lakatos (2009); Tópicos de Astrofísica e Cosmologia: uma aplicação de Física Moderna e Contemporânea no Ensino Médio (2010); A abordagem de conteúdos de Cosmologia no Ensino Médio e a proposta curricular na rede pública do Estado de São Paulo (2010) Discutindo a natureza da ciência a partir de episódios da história da Cosmologia (2011).

\footnotetext{
${ }^{1}$ Disponível em BTDEA -UFSCar - http://www.btdea.ufscar.br/
} 
Cujos respectivos autores são: Jorge Henrique Lopes de Oliveira (Universidade Estadual de Maringá- UEM); Luiz Henrique Martins Arthury (Universidade Federal de Santa Catarina- UFSC); Ricardo Rechi Aguiar (Universidade de São Paulo-USP); Roberto Pereira Farinha (Universidade Cruzeiro Sul- UNICSUL) e Alexandre Bagdonas Henrique (Universidade de São Paulo- USP).

Diante do exposto, verificou-se que há poucos pesquisadores que se preocupam em investigar se e como os conceitos inerentes a Cosmologia estão sendo abordados e discutidos no ambiente escolar e acadêmico. No entanto, os Parâmetros Curriculares Nacionais, apontam que "o universo, sua forma, seu tamanho, seus componentes, sua origem e sua evolução são temas que atraem os alunos de todos os níveis de ensino" (PCN, 1998, p. 38). Nesse sentido, para formar estudantes críticos reflexivos e atraí-los para ciência é fundamental que o professor não assente o seu saber em informações oriundas apenas de uma vertente de conhecimento, é necessário sobretudo que compreendam que "as teorias científicas, enquanto versões em construção ao longo dos tempos, evidenciaram as mudanças e a complexidade das relações entre os conceitos, assim como as próprias visões da comunidade científica de determinada época (PRAIA, CACHAPUZ, GIL-PÉREZ, 2011, p.74).

As concepções, conceitos e crenças que os professores possuem a respeito das teorias, que, supostamente regem universo, podem influenciar diretamente na visão adotada pelos estudantes em relação à Cosmologia. De acordo com Cachapuz (et al, 2005, p.61) “obter uma maior compreensão da atividade científica tem em si mesma, um indubitável interesse, em particular para quem é responsável, em boa medida, da educação científica de futuros cidadãos de um mundo impregnado de ciência e tecnologia".

Nessa perspectiva, tendo em vista a problemática da origem do universo, este trabalho tem como problema de pesquisa "O que é a Cosmologia no discurso do professor e como ela se constitui como ciência natural? ". As dissonâncias existentes entre a teoria do big bang e a do estado estacionário, desde a segunda metade do século $\mathrm{XX}$, abrangeram argumentos científicos e filosóficos, bem como princípios éticos, políticos e religiosos (KRAGH, 1996). Assim, a reflexão sobre as concepções cosmológicas e os conflitos conceituais acerca do ensino da Cosmologia se faz necessária no âmbito escolar e acadêmico, a fim de se evidenciar e discutir o caráter provisório do conhecimento científico. Para tanto, este trabalho terá como foco de estudo três evidências empíricas complexas que não permitem apenas uma 
interpretação: redshifts (desvios para o vermelho); radiação cósmica de fundo (CBR) e quasares.

Este trabalho apresenta como objetivo geral: investigar o discurso de professores e investigadores do Instituto Federal de Educação, Ciência e Tecnologia do Rio Grande do Sul (IFRS) e da Faculdade de Ciências-Universidade do Porto (FCUP) a respeito da Cosmologia contemporânea e seu ensino.

\section{CONCEPÇÕES COSMOLÓGICAS}

O estudo da origem do universo procura responder muitas inquietudes pertinentes ao homem. Para tentar entender os mistérios do universo, se faz necessário buscar respaldo nos estudos da Cosmologia, entendida como uma ciência que pretende compreender a evolução, a estrutura e a composição do universo. Nas palavras de Silk $(1985, \mathrm{p} .1)$

\footnotetext{
Cosmologia é o estudo, em larga escala, da estrutura e evolução do universo. Quando lançamos os olhos para as profundezas distantes do espaço, estamos, de fato, olhando para um tempo que já passou. Nós vemos as mais remotas galáxias tal como elas se apresentavam há milhares de anos atrás, quando suas luzes iniciaram suas longas jornadas através do tempo.
}

As informações que a humanidade tem acesso são oriundas de um passado remoto do universo e, desde milhares de gerações os seres humanos têm destinado atenção à observação do espaço em busca de respostas que representam a essência da Cosmologia - de onde viemos e para onde vamos? O conhecimento acerca do universo distante e sua origem eram muito limitados ao ponto de, propiciarem o surgimento de diversas teorias para explicar os dados observados.

Em meio ao momento histórico atual, a Cosmologia contemporânea dispõe de três principais modelos cosmológicos, sendo que um advoga em favor de um universo estacionário e os demais mostram-se favoráveis a um universo em expansão. Entretanto, vale ressaltar que estes modelos apresentam características e argumentos que divergem entre si.

O modelo cosmológico que concebe o universo em expansão foi proposto pelo físico russo George Gamow (1904-1968), no fim da década de 1940 e o mesmo ficou conhecido como big bang. Todavia, este termo, conforme ressalta Soares (2010), foi cunhado pelo astrofísico e cosmolólogo britânico Fred Hoyle de modo pejorativo, com o propósito de demonstrar o seu descontentamento com as teorias cosmológicas de expansão, originadas a partir de uma singularidade inicial, pois considerava que estas 
eram simplórias e inadequadas para a descrição do universo. A tradução geralmente empregada é "Grande Explosão", entretanto, de acordo com Soares (2010) a mesma é totalmente insatisfatória, especialmente porque trai o espírito com que o termo foi cunhado, uma vez que, rigorosamente, a tradução apropriada de Grande Explosão para o Inglês é "Great Explosion". Ao considerar que o adjetivo Big se apresenta como termo designativo do aumentativo em Inglês, o que em Português é designado pelo sufixo ão, Soares (2010) sugere que a tradução proposta para Big Bang, que satisfaz a ideia original de Hoyle, seria "Estrondão". Desse modo, optar-se-á por trazer acompanhada a tradução "estrondão" ao referir-se ao termo "big bang".

De acordo com teoria do big bang (estrondão), em resumo, o universo teria sido criado instantaneamente a partir do nada ou do vazio, há aproximadamente quinze bilhões de anos atrás, encontrando-se em expansão e resfriamento desde então. No princípio, esse universo primordial era extremamente pequeno, quente, denso e apresentava um volume inicial nulo. Tais afirmações caracterizam a chamada singularidade inicial e, de acordo com este modelo, o desvio das raias espectrais das galáxias para o vermelho (redshifts) é interpretado como sendo decorrente de um efeito Doppler óptico.

A segunda teoria cosmológica que se opõe parcialmente ao big bang (estrondão) é denominada Estado Estacionário, proposta, em 1948, por três cosmólogos britânicos de Cambridge, Hermann Bondi (1919-2005), Thomas Gold (1920-2004) e Fred Hoyle (1915-2001). Esta teoria admite a expansão do universo, porém propõe a criação contínua de matéria no decorrer do tempo e o desvio para o vermelho cosmológico também é interpretado como sendo resultado de um efeito Doppler óptico. Fred Hoyle, Geoffrey Burbidge (1925-2010) e Jayant Narlikar (1938-) publicaram um livro denominado "A Different Approach to Cosmology: From a Static Universe through the Big Bang towards Reality" (Uma abordagem diferente para Cosmologia: De um universo estático através do Big Bang para a realidade), no qual defendem amplamente este modelo.

O terceiro modelo cosmológico refere-se a um universo infinito no espaço e no tempo, em equilíbrio dinâmico, contrário a expansão e a criação contínua de matéria, com uma densidade média de matéria do universo constante. Este modelo foi apresentado e defendido por autores como Charles Édouard Guillaume (1861-1928), Erich Regener (1882-1944), Walther Nernst (1864-1941), Louis De Broglie (18921987), Erwin Finlay-Freundlich (1885-1964), Max Born (1882-1970), entre outros e 
atribui o desvio para o vermelho cosmológico a um novo princípio da natureza que não está relacionado com o efeito Doppler óptico, ou seja, não apresenta relações com a velocidade de recessão das galáxias.

\section{PROBLEMAS NO PARADIGMA VIGENTE: BIG BANG (ESTRONDÃO)}

A maioria dos filósofos da ciência contemporânea rejeita a concepção de que o desenvolvimento científico se dá, de modo, puramente linear e acumulativo. Eles concebem a ciência como uma construção humana e, portanto, admitem que o progresso científico é passível a crises, rupturas e profundas reformulações. O físico e filósofo, Thomas Kuhn, em sua principal obra “A Estrutura das Revoluções Científicas", apresenta a progresso da ciência como uma sucessão de períodos de ciência normal, interrompidos por revoluções científicas. Nos períodos de ciência normal, a academia adere a um paradigma, enquanto que, nos períodos de revoluções científicas, o paradigma vigente sofre uma ruptura. Durante o processo de transição, o antigo e o novo paradigma disputam a preferência dos membros da comunidade científica, que por sua vez, apresentam distintas visões de mundo.

A teoria do big bang (estrondão), embasada nas evidências experimentais redshits e radiação cósmica de fundo - e nas previsões teóricas, constitui-se como um paradigma da Cosmologia moderna. Segundo a concepção Kuhniana,

(Paradigma) é um resultado científico fundamental que inclui ao mesmo
tempo uma teoria e algumas aplicações tipo aos resultados das experiências e
da observação. Mais importante ainda é um resultado cuja conclusão está em
aberto e que põe de lado toda uma espécie de investigação ainda por fazer. E,
por fim, é um resultado aceite no sentido de que é recebido por um grupo
cujos membros deixam de tentar opor-lhe rival ou de criar-lhe alternativas
(KUHN, 1974, apud, NEVES, 2000a, p.192).

Conforme mencionado anteriormente, este artigo procura centrar-se em três evidências empíricas complexas que possuem distintas interpretações, são elas: redshifts (desvios das raias espectrais para o vermelho); radiação cósmica de fundo (CBR) e quasares.

Em relação à primeira evidência empírica pode-se afirmar que renomado astrônomo Edwin Powell Hubble ao realizar suas pesquisas junto ao Observatório de Monte Wilson com a ajuda do telescópio de cem polegadas e 2,5 m, descobriu um padrão de medidas para distâncias intergalácticas (NEVES, 2011). E observando a galáxia de Andrômeda, Hubble obteve êxito ao conseguir separar dos ramos em espiral, as cefeidas, familiares a uma classe de estrelas da Via Láctea. 
A partir das observações realizadas da luminosidade aparente das Cefeidas na nebulosa de Andrômeda e estimando, a partir dos respectivos períodos, a luminosidade absoluta, Hubble determinou a respectiva distância e, consequentemente a distância da nebulosa da Andrômeda, usando a regra simples de que a luminosidade aparente é proporcional à luminosidade absoluta e inversamente proporcional ao quadrado da distância (WEINBERG, 1980). O resultado encontrado por Hubble não correspondia com o valor da distância que se sabe atualmente, contudo o método empregado por ele era essencialmente correto.

Ao final da segunda década do século XX, Hubble já havia feito medidas de galáxias suficientes para perceber que, com exceção de nossas galáxias vizinhas mais próximas, tal como a Andrômeda, todas as demais galáxias pareciam se afastar de nós. Além disso, a velocidade de afastamento de cada galáxia (velocidade de recessão) se mostrava proporcional à distância entre a respectiva galáxia e a Terra e quanto mais afastada a galáxia, maior parecia sua velocidade de recessão.

Nesse mesmo período, com base nos seus estudos, Hubble anunciou que o deslocamento para o vermelho das linhas espectrais das galáxias (redshifts),

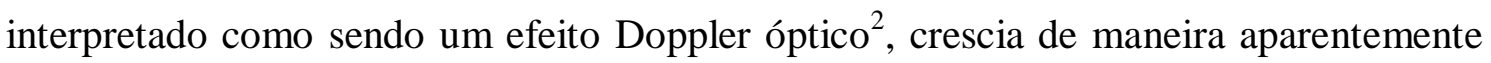
proporcional à distância entre a galáxia e a Terra. Contudo, apesar das observações de Hubble serem consistentes com a teoria de um universo em expansão, estas não são necessariamente uma confirmação incontestável e definitiva dela, uma vez que, o renomado astrônomo procurou, insistentemente, compreender o que causaria os desvios para o vermelho (ASSIS; NEVES; SOARES, 2008).

Neves (2000a) salienta que os pesquisadores favoráveis a teoria de um universo estacionário, interpretam o redshift como sendo um efeito decorrente da perda de energia do fóton de luz em sua longa jornada através do espaço (um decaimento da

\footnotetext{
${ }^{2}$ O fenômeno ou efeito Doppler é um fenômeno físico e, graças a ele, é possível mensurar se uma fonte sonora ou luminosa se aproxima ou se afasta de um observador. O caso sonoro é bastante conhecido: quando um carro de bombeiros se aproxima de nós, observadores-ouvintes, com a sirene ligada, ouvimos um som muito agudo (as frentes de onda se concentram à frente da onda, diminuindo o comprimento das ondas e, portanto, aumentando a frequência. No caso oposto, quando o caminhão se afasta, o som da sirene torna-se mais grave (as ondas sofrem uma espécie de "alargamento", tornando-se maiores, o que, em consequência, diminui a frequência). Para o caso luminoso, o feito é o mesmo: para fontes que se afastam, linhas espectrais tendem a deslocar-se para a extremidade vermelha do espectro (grande comprimento de onda, baixa frequência) - esse é o que os astrônomos batizaram de " desvio para o vermelho (redshift)"; para fontes que se aproximam, as linhas espectrais tendem a deslocar-se para a extremidade azul do espectro (pequeno comprimento de onda, alta frequência) - blueshift (deslocamento para o azul) " (NEVES, 2011, p. 194).
} 
frequência do fóton de luz). Tal interpretação ficou conhecida como teoria da "luz cansada".

As teorias de "luz cansada" caracterizam-se como tentativas de oferecer explicações distintas para os redshifts. Halton Arp, por exemplo, ao rejeitar a hipótese de um universo evolutivo, propõe, com base em dados observacionais que os mesmos são indicativos da idade da matéria e, portanto, são intrínsecos a quasares e galáxias.

Já em relação à radiação cósmica de fundo (CBR), pode-se dizer que a mesma foi descoberta acidentalmente por Penzias e Wilson em 1965. A detecção desta radiação de fundo de micro-ondas ${ }^{3}$, que preenche o universo, foi o avanço cosmológico mais importante desde a descoberta dos deslocamentos para o vermelho (redshifts) (WEINBERG, 1980). Muitos estudiosos defendem a ideia de que a radiação é oriunda diretamente do próprio big bang (estrondão) com uma temperatura muito elevada e que na medida em que o universo foi se dilatando e resfriando a mesma foi diminuindo até atingir o valor de 2,7 K. Apesar da radiação de micro-ondas ter sido descoberta na década de 1960, somente em abril de 1992 ela virou notícia, quando os jornais do mundo inteiro publicaram na primeira página, imensas manchetes relatando a descoberta, anunciada um dia antes em um Congresso da American Physical Society, em Washington. Afirmando-se na ocasião que, a radiação de fundo não era perfeitamente uniforme, mas apresentavam minúsculas ondulações na radiação de fundo, “[...] as quais correspondem a igualmente minúsculas flutuações de temperatura da energia da radiação de micro-ondas que nos alcançam, provenientes de diversas regiões do espaço" (GRIBBIN, 1995, p.20-21). Essas minúsculas ondulações da radiação, foram interpretadas como sendo decorrentes das variações de densidade no universo primordial, que supostamente, teriam dado origem a formação das galáxias. A descoberta dessas irregularidades foi feita por cientistas que trabalhavam na Califórnia, usando instrumentos a bordo de um satélite da Terra não tripulado enviado pela NASA e denominado COBE, nome oriundo das iniciais de "Cosmic Background Explorer" (GRIBBIN, 1995).

Referente à descoberta feita pelo $\mathrm{COBE}$, muitos cientistas, defensores da teoria do big bang (estrondão), enfatizam que a mesma foi de extrema importância, pois as ondulações da radiação de fundo encontradas instituem-se como sendo uma peça fundamental que faltava para explicar a origem e, suposta evolução do universo.

\footnotetext{
3 "Micro-onda é o termo usado pelos radioastrônomos para designar as ondas de rádio de pequeno comprimento (aquelas com comprimento de onda inferior a alguns centímetros) " (SILK, 1985, p. 77).
} 
Contudo, para Arp (2001) as irregularidades da CBR correspondem a um argumento a favor de um universo que não se expande, uma vez que, isso acontece porque o meio intergaláctico pode ser observado daqui até um ponto tão distante quanto se queira sem qualquer distorção da velocidade devido à expansão. De acordo com o autor, "a interação através desta maior distância possível é a que é mais capaz de suavizar todas as flutuações na radiação de fundo recebida de todas as profundezas do universo" (ARP, 2001, p.352). Nesse sentido, para o universo sem expansão a explicação mais eloquente e mais simples para a CBR é a de que estamos vendo simplesmente a temperatura no meio intergaláctico subjacentes (ARP, 2001).

Ademais, Neves (2000a) apresenta uma revisão histórica onde aborda evidências teóricas comprovando que os modelos de estado estacionário previram valores da temperatura da radiação cósmica de fundo, muito mais próximos, do que os valores teóricos apontados pelos defensores de um universo evolucionário.

Por fim, a respeito dos quasares é possível assegurar que estes são objetos astronômicos de um tipo especial, pois apesar de apresentarem características semelhantes às estrelas, não são considerados estrelas. Conferiram a eles o nome de "quasar" como abreviação de quase-stellar optical object (QSO), que corresponde a “objeto óptico quase estelar" Os quasares foram descobertos, em 1963, pelo astrônomo Maarten Schimidt.

Discutiu-se, por muito tempo, se os quasares seriam objetos da Via Láctea ou de fora dela, mas, atualmente, acredita-se que eles estão fora da nossa galáxia, situados a distâncias extremas, configurando-se como os objetos mais longínquos do universo. Os quasares são poderosamente energéticos e irradiam uma quantidade enorme de luz, que pode ser até cem vezes superior do que todas as estrelas da Via Láctea juntas. No entanto, não são objetos muito grandes, por isso, provavelmente tenham sido confundidos, incialmente, com estrelas, uma vez que, seu tamanho deve ser dez mil vezes menor do que o de uma galáxia.

Os quasares podem apresentar grandes desvios para o vermelho de sua luz. Se os mesmos forem interpretados, como sendo decorrentes da velocidade com que estão afastando-se da Via Láctea, concluir-se-ia, portanto, que estão se distanciando à uma velocidade de $90 \%$ da velocidade da luz. Há, contudo, muitos questionamentos sobre a possibilidade de os quasares não serem tão luminosos e remotos, como acreditam a maioria dos astrônomos. Se os desvios para o vermelho não forem cosmológicos, estes 
objetos podem estar mais próximos da Via Láctea, aproximadamente, a apenas alguns milhões de anos-luz. Nas palavras de Arp (2001, p.15).

Halton Arp (1927-2013) foi um observador habilidosos e muito experiente e, por meio de uma série de fotografias tiradas e medições realizadas, ele concluiu que os quasares estavam associados fisicamente a uma galáxia, bem como constatou que, quando havia dois ou mais quasares próximos das galáxias, estes estavam localizados em lados opostos. Contudo, a comunidade científica interpretou os seus dados observacionais, como sendo devidos a uma sobreposição de imagens, que com efeito, fazia com que parecessem próximos.

No que se refere ao nascimento das galáxias, o renomado astrônomo, em suas obras "Universo Vermelho" e "Quasars, Redshifts and Controversies", propõe que "[...] elas são ejetadas de galáxias mais velhas como objetos compactos com massas pequenas. À medida que estas galáxias novas envelhecem e crescem em massa e tamanho, elas emitem, por sua vez, novas gerações num processo de cascata" (ARP, 2001, p.23). Nessa perspectiva, para Arp, o quasar pode ser a ejeção de matéria de um núcleo galáctico, o que implicaria diretamente nos elevados redshifts dos quasares associados a galáxias, que, por sua vez, apresentam baixos redshifts.

Tais concepções diferem da visão convencional, que consiste em supor, que as galáxias estão condensando-se a partir de um gás quente e tênue, que impregna homogeneamente o espaço. E, por apresentar e discutir observações que contradizem os teóricos do modelo do big bang (estrondão), as pesquisas de Arp eram julgadas improcedentes pelos avaliadores das principais revistas da área, uma vez que, consideram que se tratavam de casos isolados

Em suma, as associações físicas entre os quasares, com altos redshifts, e as galáxias, com baixos redshifts, constituem-se como uma anomalia na teoria do big bang (estrondão). Segundo a concepção Kuhniana, uma anomalia refere-se a um fenômeno, para o qual o paradigma da ciência normal não prepara o cientista e, quando a comunidade científica reconhece que, de alguma maneira, a natureza violou as expectativas paradigmáticas que governam a ciência normal, dá-se início

[...] então, uma exploração mais ou menos ampla da área onde ocorreu a anomalia. Esse trabalho, somente se encerra quando a teoria do paradigma for ajustada, de tal forma que o anômalo se tenha convertido no esperado. A assimilação de um novo tipo de fato exige mais do que um ajustamento aditivo da teoria. Até que tal ajustamento tenha sido completado - até que o cientista tenha aprendido a ver a natureza de um modo diferente - o novo fato não será considerado completamente científico (KUHN, 2013, p.128). 
Com a descoberta dos quasares e suas implicações, instaurou-se, entre os membros da comunidade científica, uma série de questionamentos e tentativas de explicações a fim de fazer com que a teoria do big bang (estrondão) continuasse sendo a mais aceita. Nessa perspectiva, é possível compreender por que os dados observacionais de Halton Arp não tiveram o merecido prestígio, pois, se os mesmos estivessem corretos, a academia seria conduzida a abandonar a teoria do big bang (estrondão) e, desse modo, teria que adotar uma visão completamente distinta do espaço extragaláctico. Contudo, Arp recebeu o apoio de influentes pesquisadores, como Geoffrey Burbidge e Margaret Burbidge, que assim como ele, defendem a hipótese local dos quasares.

\section{ENCAMINHAMENTOS METODOLÓGICOS}

Com o propósito de contribuir para desvelar o problema central da pesquisa " $\mathrm{O}$ que é a Cosmologia no discurso do professor e como ela se constitui como ciência natural"? buscou-se realizar entrevistas com professores e investigadores, de acordo com os pressupostos teóricos e metodológicos da pesquisa fenomenológica, de duas instituições de ensino superior, sendo uma nacional e a outra internacional.

O estudo desenvolvido teve como campo de pesquisa o Instituto Federal de Educação, Ciência e Tecnologia do Rio Grande do Sul (IFRS) e a Faculdade de Ciências da Universidade do Porto, Portugal. A primeira instituição de ensino superior foi escolhida em decorrência de ofertar o curso de Licenciatura Plena em Física o qual, em sua matriz curricular disponível em endereço eletrônico, consta a disciplina de “Tópicos de Astronomia", cuja ementa prevê a abordagem de "Tópicos de Cosmologia (Expansão e modelos de Universo) ".

Já a oportunidade de desenvolver a investigação na Universidade do Porto surgiu por intermédio do Programa de Mobilidade Internacional promovido pelo Escritório de Cooperação Internacional-Universidade Estadual de Maringá (ECI-UEM). A referida instituição também oferece o curso de Licenciatura em Física e de acordo com o seu plano de estudos, no segundo semestre do curso é disponibilizado a disciplina de "Tópicos de Física Moderna e Astrofísica", cujo objetivo consiste em proporcionar aos estudantes uma introdução histórica e conceitual sobre a Cosmologia.

A pesquisa caracteriza-se como sendo fenomenológica, uma vez que esta

[...] trabalha sempre com o qualitativo com o que faz sentido para o sujeito, com o fenômeno posto em suspensão como percebido e manifesto pela linguagem; e trabalha também com o que se apresenta como significativo ou 
relevante, no contexto no qual a percepção e a manifestação ocorrem (BICUDO, 2000, p. 74).

Segundo esta abordagem, inicialmente é necessário situar o fenômeno, uma vez que o mesmo somente existe com a condição de que haja um sujeito, no qual ele possa situar-se. Com o objetivo de saber o que faz sentido para o sujeito, a pesquisa fenomenológica, procura ir-à-coisa-mesma, não se restringindo à busca por conceitos e ideias que tratem somente da coisa (BICUDO, 2000). Nesse sentido, buscou-se definir os interlocutores a fim de investigar como os mesmos percebem e significam o ensino da Cosmologia contemporânea.

Os sujeitos da investigação foram 3 (três) docentes que ministram aulas para o curso de Licenciatura Plena em Física do IFRS-BG e 3 (três) professores/investigadores que desenvolvem pesquisas na área da Cosmologia junto ao Centro de Astronomia e Astrofísica da Universidade do Porto (CAUP), Portugal.

A fenomenologia interessa-se em compreender os atos intencionais, o vivido, o mundo da vida, os correlatos intencionais (HUSSERL, 2001). Nessa perspectiva, optouse por adotar, como estratégia de coleta de dados, entrevistas filmadas, pois por meio das mesmas é possível imergir nas concepções dos interlocutores, ou seja, a entrevista favorece a compreensão das crenças, opiniões, valores e significados que os interlocutores atribuem aos fatos e fenômenos.

O investigador fenomenológico preocupa-se com a natureza do que se propõe a investigar, de modo que, não há, para ele uma compreensão prévia do fenômeno, pois, "ele não possui princípios explicativos, teorias ou qualquer indicação definidora do fenômeno" (MARTINS; BICUDO,1989, p. 92). O pesquisador inicia a sua investigação interrogando diretamente o fenômeno, sem ter conhecimento das características essenciais do mesmo. E, quando surgem dúvidas a respeito do fenômeno pesquisado, a postura do fenomenólogo é importante, uma vez que ele precisa respeitá-las e procurar "[...] mover-se lenta e cuidadosamente de forma que ele possa permitir aos seus sujeitos trazerem à luz o sentido por eles percebidos sobre o mesmo" (MARTINS; BICUDO, 1989, p. 92).

Nesse contexto, as entrevistas não apresentavam roteiros pré-estabelecidos, mas sim eram guiadas por uma interrogação significativa, que, com efeito, pretendia captar a essência do fenômeno. Considerando o objetivo da pesquisa, que consiste em investigar o discurso de professores/ investigadores sobre o ensino da Cosmologia contemporânea, fez-se a seguinte indagação “O que é a Cosmologia para você?”. E, 
conforme os fundamentos fenomenológicos, nesse momento os pressupostos teóricos e conceituais ficaram suspensos, isto é, foi realizado a "epoché". Este rigor fenomenológico permite ao fenômeno mostrar-se nas multiplicidades de suas formas

As entrevistas com os sujeitos de pesquisa foram filmadas e, posteriormente, transcritas a fim de que fosse possível o início das descrições das mesmas. Ao transcrever os discursos dos interlocutores da investigação e o modo como eles se deram obteve-se as descrições. Para ajudar na análise das descrições, Bicudo e Martins (1989) sugerem que, incialmente estas sejam lidas na íntegra visando familiarizar-se com o texto que descreve a experiência vivida. Nesse momento, segundo os referidos autores, o pesquisador carece de "[...] colocar-se no lugar do sujeito e tentar viver a experiência vivida pelo sujeito, de forma que ele não seja um mero espectador, mas alguém que procura chegar aos significadores atribuídos vivencialmente" (MARTINS; BICUDO, 1989, p.95).

As descrições não comportam avaliações e opiniões do sujeito sobre a experiência vivida, mas sim relatam "[...] de modo tão preciso quanto possível, o que ocorre com ele ao viver suas experiências" (MARTINS; BICUDO, 1989, p. 94). Todavia, como a investigação fenomenológica vai além da descrição, deu-se início ao processo de redução, onde as descrições foram lidas repetidamente a fim de descartar os discursos considerados "ingênuos" e destacar as Unidades de Significados “[...] dispondo-as em forma das asserções e indicando, o mais fielmente possível, as ideias articuladas no discurso" (BICUDO, 2000, p. 86-87).

Após reler as descrições, quantas vezes forem necessárias, objetiva-se discriminar as Unidades de Significados, que referem a fragmentos dos discursos que são entendidos como significativos, iniciou-se a compreensão da Situação Relatada na Unidade de cada unidade destacada. Em seguida, foi realizado o processo de Compreensão Ideográfica de cada sujeito, que se refere ao "emprego de ideogramas, ou seja, de representações de ideias por meio de símbolos. Efetivamente, trata-se da análise da ideologia que permeia as descrições ingênuas do sujeito" (MARTINS; BICUDO, 1989, p.101).

Para finalizar a pesquisa, buscou-se chegar às categorias, as quais "[...] expunham as grandes convergências e indicavam as características do fenômeno que abrangiam" (BICUDO, 2000, p.84). Esta etapa, denominada de Compreensão Nomotética do conjunto de sujeitos, refere-se à compreensão das convergências presentes nos discursos de cada interlocutor e, posteriormente, as convergências entre os 
discursos. O objetivo desta etapa é chegar à estrutura geral psicológica. Por último, após definidas as categorias, foi realizado a Compreensão Eidética das mesmas, procurando analisar as convergências de cada categoria.

\section{RESULTADOS E DISCUSSÕES}

Neste momento serão apresentadas as unidades de significado extraídas do discurso e posteriores compreensões das mesmas de apenas um dos sujeitos de pesquisa que diz respeito ao interlocutor 2. Contudo, a compreensão nomotética das situações relatadas e a compreensão nomotética geral referem-se aos discursos dos seis sujeitos de pesquisa $^{4}$.

\section{UNIDADES DE SIGNIFICADO E COMPREENSÕES DAS SITUAÇÕES RELATADAS}

Unidade de Significado 1

"Hãm... Cosmologia é essencialmente o estudo da origem e evolução do universo, portanto, é uma, é essencialmente a aplicação de física, portanto, as leis da física, os princípios da Física ao estudo do universo como um todo, portanto, o universo em larga escala".

Compreensão da situação relatada na unidade 1

O interlocutor versa sobre a Cosmologia, buscando simplifica-la, de modo que esta se resume ao estudo da origem e evolução do universo, em grande escala, a partir da aplicação de leis e princípios físicos. As demais áreas de investigação que contribuem para o estudo do universo como um todo não são mencionadas, fazendo com que transpareça a ideia que o estudo do cosmos se dá, exclusivamente, pelo conhecimento inerente à Física.

O sujeito 2, inicialmente, expressa o seu entendimento sobre Cosmologia de forma precisa e objetiva, demonstrando com isso, estar apoiado em uma definição, comumente encontrada em bibliografias da área, que não carece de muitas explicações, em primeira aproximação.

Unidade de Significado 2

"Hãm... Aquilo que nós sabemos é que o universo começou, pelo menos a região do universo que nós observamos começou num estado extremamente quente, extremamente denso, hãm... Muito mais simples, simples do ponto de vista da física, há uma definição técnica de simplicidade em Física, se você quiser podemos

\footnotetext{
${ }^{4}$ A análise e discussão dos resultados na íntegra encontram-se disponível na dissertação de mestrado intitulada "O discurso sobre a Cosmologia contemporânea nas diferentes falas da academia" (MARTINS, 2016).
} 
falar disso mais tarde hãm... Começou nesse estado simples mais quente e denso e a partir daí foi evoluindo, portanto foi expandindo, arrefecendo e gradualmente foram se formando as estruturas que nós observamos em grande escala, as galáxias, os enxames de galáxias, etc. E esse processo de evolução das estruturas é essencialmente um processo gravitacional que se deve ao fato da interação gravitacional ser sempre uma força atrativa, mas precisa de mecanismos para gerar flutuações iniciais de densidade, são esses mecanismos é uma questão um pouco diferente das que hoje em dia estão a estudar, está a teoria do big bang (estrondão) muito bem fundamentada."

Compreensão da situação relatada na unidade 2

Ao valer-se do vocábulo "nós sabemos", o interlocutor deixa transparecer que o seu conceito a respeito de Cosmologia vai ao encontro das concepções apresentadas por outros membros da comunidade científica. Já o emprego do termo "simples" em Física é mencionado pelo sujeito ao referir-se ao começo do universo, contudo a explanação da sua definição é postergada.

Neste segundo momento, o discurso apresenta, de forma detalhada, o processo de origem e estruturação do universo. Tais afirmações indicam que o mesmo teve um início, extremamente quente e denso, e posteriormente, na medida em que foi expandindo, foi sofrendo um resfriamento e formando as estruturas que são observadas em larga escala. Segundo essa concepção, que corresponde à teoria do big bang (estrondão), as elucidações sobre o surgimento, evolução e desenvolvimento do universo estão respondidas, embasadas em fundamentos confiáveis.

\section{Unidade de Significado 3}

"Eu acho que até a pouco tempo, até a vinte anos digamos a Cosmologia era uma aérea de exploração livre no sentido do que quase não havia dados observacionais, portanto havia imensas teorias poderiam ser postuladas, muito dificilmente eram separáveis ( ), hoje não é o caso, Cosmologia é totalmente liderada e impulsionada, catalisada por resultados observacionais, portanto é extremamente difícil a existência de modelos alternativos que estejam em desacordo com, com a descrição global que temos do universo, as teorias podem diferir em pequenos detalhes, teorias são, não são necessariamente fáceis de testar como já testamos atualmente, mas em termos de visão global se quiseres, estrutura global da teoria, imagem conceitual, essa, essa (sic) imagem está muito bem conhecida do ponto de vista observacional, portanto é praticamente impossível ter uma descrição que seja completamente diferente dessa..."

Compreensão da situação relatada na unidade 3

Um breve resgate histórico é feito, a fim de tentar justificar o porquê diversas teorias emergiram no campo da Cosmologia, no decorrer da história. Contudo, o discurso revela que, atualmente, postular modelos cosmológicos, que não estejam de acordo com a teoria do big bang (estrondão) é uma tarefa árdua e improvável, visto que, segundo o ponto de vista do sujeito 2 os dados observacionais que o homem dispõe, fornecem suporte suficiente para descrever adequadamente o universo. 
A postura do interlocutor exteriorizou certo incômodo ao ser instigado a refletir sobre suas concepções cosmológicas, pois o mesmo mostrou-se enérgico ao tecer suas considerações incisivamente, atribuindo demasiada importância às interpretações observacionais derivadas do modelo cosmológico padrão.

Unidade de Significado 4

“[...] isso não quer dizer que a visão que temos do mundo atualmente seja completamente correta e de fato há coisas que nós não sabemos, $96 \%$ do conteúdo do universo são coisas que chamamos de matéria escura, energia escura que nós nunca detectamos em laboratório, deveria ser indireta observacional pelo fato delas existirem, mas nunca as vimos em laboratório, então da mesma forma que, já vimos um elétron um próton no laboratório..."

Compreensão da situação relatada na unidade 4

Já desta unidade o interlocutor evidencia a incipiência do conhecimento humano frente aos constituintes do universo. Nessa perspectiva, o discurso busca justificar o porquê supõe-se a existência de entidades desconhecidas e até então não detectadas em laboratório.

O sujeito 2 traz para o discurso o fato que é possível detectar um próton ou um elétron em laboratório, todavia ele deixa implícito que tais evidências somente foram possíveis, após a previsão teórica das mesmas. Dessa forma, percebe-se que o interlocutor considera importante a postulação de princípios teóricos para o desenvolvimento da ciência, em especial na área da Cosmologia.

Unidade de Significado 5

“[...] há três pilares observacionais do modelo padrão da Cosmologia, chamado modelo do big bang. O primeiro é o fato de o universo estar a expandir e as escalas das galáxias, galáxias se afastarem entre si com uma velocidade que pelo menos em uma primeira aproximação é proporcional à distância entre elas, isso chama lei de Hubble que não é completamente rigorosa, mas é uma boa aproximação, portanto é válida a escalas quilômetros por um, hoje em dia, se fizer essas observações em escalas muito, muito grandes hãm... Há pequenas correções, que são correções relativísticas que têm a ver com a curvatura do universo, etc. Mas em primeira aproximação a lei de Hubble é válida e uma aproximação direta do modelo, portanto que foi confirmada, portanto esse é o primeiro pilar. O segundo é, é aquilo que chamamos da síntese primordial, abundância primordial dos elementos leves, o hidrogênio, o hélio, o lítio foram formados no início do universo, mais ou menos nos três primeiros minutos do universo e o modelo prevê isso muito bem, consegues prever todas essas abundâncias que tendo apenas um parâmetro livre, que é essencialmente o quociente entre o número de bários, prótons, nêutrons e o número de fótons que está em exceção e esse único parâmetro controla todas as abundâncias ativas desses elementos, portanto isso também está muito bem estudado, muito bem documentado, e o terceiro que a existência de algumas propriedades mais simples da radiação cósmica de fundo, a radiação cósmica de micro-ondas, o universo por já hãm... Uma vez já foi mais quente e mais denso, essa radiação primordial ainda está no universo, por definição não é nada fora do universo simplesmente esse ponto de radiação é hoje muito mais frio, com uma temperatura de aproximadamente $2,7 \mathrm{~K}$ hãm... E essa temperatura foi 
detectada e não só foi detectada, mas as propriedades estatísticas dessa temperatura são conhecidas, foram caracterizadas e mais uma vez estão ( ) se quiseres em primeira aproximação são as três grandes previsões do modelo do big bang que foram confirmadas."

Compreensão da situação relatada na unidade 5

O discurso considera que a solidificação da teoria do big bang (estrondão) se dá por evidências puramente observacionais. Sendo a primeira delas inerente às contribuições da lei de Hubble, a segunda refere-se à síntese primordial, ou seja, a abundância dos elementos leves e já a terceira evidência diz respeito à detecção da radiação cósmica de fundo. O sujeito 2 versa sobre os três pilares do modelo cosmológico padrão, evidenciando ter pleno domínio sobre o assunto. Seus argumentos são eloquentes, derivados provavelmente de sua dedicação e estudo, enquanto pesquisador destes temas.

Segundo as referidas previsões, o interlocutor defende que a teoria do big bang (estrondão) apresenta dados observacionais e teóricos confiáveis o bastante para ser considerada a teoria que melhor fornece explicações sobre a constituição e evolução do universo.

Unidade de Significado 6

“[...] é importante para toda a gente ter pelo menos uma ideia básica, sem os detalhes técnicos obviamente, mas ter, ter (sic) uma ideia básica da visão do universo, da cultura em que se vive".

Compreensão da situação relatada na unidade 6

Neste fragmento, o sujeito 2 mostra-se favorável à difusão do conhecimento científico inerente às concepções cosmológicas, de modo acessível às pessoas, para que assim estas possam compreender, ainda que minimamente, o universo em que vivem.

Unidade de Significado 7

“[...] o modelo do big bang no contexto da química, essencialmente na formação dos elementos da tabela periódica, eles precisam saber que os elementos mais leves foram formados no início do universo, os elementos até o ferro foram formados nas estrelas, os elementos a partir daí foram formados nas explosões de supernovas etc".

Compreensão da situação relatada na unidade 7

O discurso situa e exemplifica a importância de ensinar o modelo do big bang (estrondão) no contexto do ensino de química. Contudo, por meio da fala do sujeito 2, é possível inferir que o mesmo somente atribui relevância ao enfoque conteúdista, ou seja, ele demonstra não considerar fundamental a reflexão e discussão de aspectos relativos à natureza de ciência. 


\section{COMPREENSÃO IDEOGRÁFICA DO SUJEITO DE PESQUISA}

O sujeito 2 demonstra que a partir da aplicação das leis e princípios físicos é possível entender os fatos e fenômenos ocorridos no decorrer da evolução e estruturação do universo observável. A compreensão do interlocutor sobre Cosmologia é pautada nos pressupostos teóricos inerentes à teoria do big bang (estrondão), pois de acordo com o sujeito 2, estes fornecem explicações coerentes e satisfatórias aos resultados observacionais e, portanto, são dignos de confiança.

Percebe-se que as concepções do sujeito 2 são compatíveis com os conceitos cosmológicos encontrados em artigos e livros de divulgação científica, escritos por renomados membros da comunidade científica. Desse modo, entende-se que seja em decorrência desse suporte teórico associado com a trajetória acadêmica e profissional do sujeito 2, que o mesmo discursa demonstrando segurança e domínio sobre as evidências empíricas e observacionais que alicerçam o modelo cosmológico padrão.

O sujeito 2 reconhece que no decorrer da história, vários modelos cosmológicos foram postulados, na tentativa de buscar respostas para as inquietações da humanidade, contudo, o mesmo argumenta que tais previsões não são mais aceitas, visto que, em consequência dos dados observacionais que o homem dispõe, não há mais espaço para dúvidas e problemas que estejam em desacordo com a teoria do big bang (estrondão).

O interlocutor 2 também evidencia que a Cosmologia necessita fazer previsões teóricas e supor a existência de entidades desconhecidas para tentar encaixar todas as peças do quebra-cabeças. Desse modo, o sujeito 2 deixa implícito que as lacunas desse quebra-cabeça são importantes para o desenvolvimento da Cosmologia, entendida como uma ciência que busca compreender o universo em sua completude.

Em relação ao ensino da Cosmologia, o sujeito 2 considera relevante os estudantes aprenderem, de acordo com uma metodologia adequada, conceitos e conteúdos referentes ao universo em que habitam, para que assim consigam situar-se e compreenderem o espaço que ocupam dentro do mesmo.

Na tabela abaixo são apresentadas as convergências encontradas nos discursos dos sujeitos de pesquisa e as categorias que emergiram a partir das convergências das unidades de significado. 


\section{AS CONVERGÊNCIAS DOS DISCURSOS DOS SUJEITOS}

Tabela 1: As convergências dos discursos, agrupadas segundo as categorias encontrada

\begin{tabular}{|c|c|c|c|c|c|c|}
\hline \multirow{2}{*}{ CATEGORIAS } & \multicolumn{6}{|c|}{ CONVERGÊNCIAS } \\
\hline & Sujeito 1 & Sujeito 2 & Sujeito 3 & Sujeito 4 & Sujeito 5 & Sujeito 6 \\
\hline 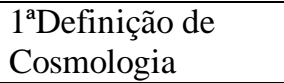 & 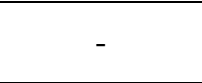 & $\mathrm{U}-1^{5}$ & U-1 & U-1 & $\mathrm{U}-1, \mathrm{U}-2$ & U-1 \\
\hline $\begin{array}{l}2^{\mathrm{a}} \text { Cosmologia } \\
\text { como ciência }\end{array}$ & $\begin{array}{c}\text { U-1, U-2, U- } \\
3, \text { U-5, U-6, } \\
\text { U-7, U-9, U- } \\
10, \text { U-12 }\end{array}$ & - & - & U-5 & - & - \\
\hline $\begin{array}{l}3^{\text {a } I m p o r t a ̂ n c i a ~ d o s ~} \\
\text { resultados } \\
\text { observacionais }\end{array}$ & 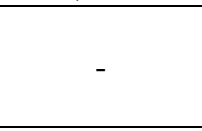 & U-3 & U-5 & - & - & - \\
\hline $\begin{array}{l}4^{\mathrm{a}} \text { Importância do } \\
\text { contexto histórico } \\
\text { e social }\end{array}$ & $\begin{array}{c}\mathrm{U}-1 \mathrm{U}-2, \mathrm{U}- \\
6\end{array}$ & - & - & - & - & - \\
\hline $\begin{array}{l}5^{\text {a }} \text { A importância } \\
\text { de fazer } \\
\text { suposições no } \\
\text { campo da } \\
\text { Cosmologia }\end{array}$ & $\begin{array}{l}\mathrm{U}-2, \mathrm{U}-3, \mathrm{U}- \\
5, \mathrm{U}-6\end{array}$ & U-4 & - & - & - & - \\
\hline $\begin{array}{l}6^{\mathrm{a} C o s m o l o g i a} \\
\text { como área de } \\
\text { integração }\end{array}$ & U-8 & - & - & - & - & - \\
\hline $\begin{array}{l}7^{\text {a }} \text { Teoria do big } \\
\text { bang (estrondão) e } \\
\text { os seus pilares } \\
\text { teóricos e/ou } \\
\text { experimentais }\end{array}$ & U-10, U-11 & $\mathrm{U}-2, \mathrm{U}-5$ & $\begin{array}{l}\text { U-2, U-3, } \\
\text { U-4 }\end{array}$ & $\mathrm{U}-2, \mathrm{U}-4$ & $\mathrm{U}-3$ & $\mathrm{U}-2, \mathrm{U}-3$ \\
\hline 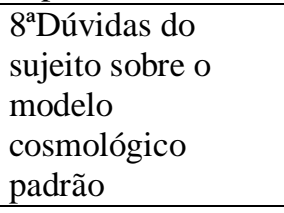 & - & - & - & U-3 & $\mathrm{U}-4$ & - \\
\hline $\begin{array}{l}9^{\mathrm{a}} \text { Ensino da } \\
\text { Cosmologia }\end{array}$ & $\mathrm{U}-3, \mathrm{U}-4$ & U-6, U-7 & U-6, U-7 & U-5 & U-6 & $\mathrm{U}-4$ \\
\hline $\begin{array}{l}10^{\mathrm{a}} \text { Insegurança e } \\
\text { receio ao falar } \\
\text { sobre Cosmologia }\end{array}$ & - & - & - & U-1 & $\begin{array}{l}\text { U-1, U-2, } \\
\text { U-3, U-6 }\end{array}$ & U-1 \\
\hline
\end{tabular}

\section{COMPREENSÃO EIDÉTICA DAS CONVERGÊNCIAS NA PRIMEIRA CATEGORIA: DEFINIÇÃO DE COSMOLOGIA}

Os interlocutores discorrem sobre suas concepções a respeito da Cosmologia. E, estas definições convergem para a ideia que esta ciência se destina ao estudo do universo, desde o seu início até sua estruturação e possível evolução. Percebe-se que os

\footnotetext{
5 U-1 diz respeito a Unidade de Significado 1, U-2 a Unidade de Significado 2 e assim sucessivamente.
} 
discursos não apresentam divergências quanto à compreensão, contudo diferem no que se refere à abrangência de suas argumentações, pois, alguns sujeitos descrevem seu entendimento acerca da Cosmologia, de modo sucinto e por vezes, impreciso.

O estudo do universo, segundo as perspectivas dos sujeitos de pesquisa, é complexo e intrigante, uma vez que, implica questões que o homem ainda não conseguiu responder, em decorrência de se deparar com escalas muito grandes, as quais não são passíveis de observações.

\section{COMPREENSÃO EIDÉTICA DAS CONVERGÊNCIAS NA SEGUNDA CATEGORIA: COSMOLOGIA COMO CIÊNCIA}

A Cosmologia entendida como uma ciência que não apresenta um método único e universal que norteia a atividade científica está evidente no discurso do sujeito 4 e principalmente no sujeito 1. Ambos compreendem que a Cosmologia não se desenvolve por meio de um método rígido e restritivo, mas pelo contrário o conhecimento científico inerente à mesma é derivado do esforço de muitos cientistas, os quais em suas trajetórias cometem equívocos, elaboram e reformulam hipóteses, a fim de tentar solucionar os problemas que lhe são propostos.

Nos demais discursos, percebe-se que há muitas lacunas quanto à compreensão da Cosmologia como ciência. Tal fato permite depreender que os outros sujeitos de pesquisa, em determinados momentos de suas respectivas falas, colocam a Cosmologia no campo das certezas e, portanto, desconsideram que o conhecimento científico que se tem acesso atualmente, apresenta um caráter provisório, que pode ser confrontado e modificado no decorrer do desenvolvimento de modelos cosmológicos.

\section{COMPREENSÃO EIDÉTICA DAS CONVERGÊNCIAS NA TERCEIRA CATEGORIA: IMPORTÂNCIA DOS RESULTADOS OBSERVACIONAIS}

Nessa categoria os dados observacionais configuram-se como uma comprovação do modelo cosmológico padrão. É atribuída excessiva importância aos mesmos. Como a Cosmologia é uma ciência observacional, os resultados observacionais merecem prestígio e consideração, todavia estes podem ter diferentes interpretações, oriundas de pesquisadores que os compreendem segundo teorias distintas e, portanto, também merecem e atenção e respaldo.

Já nos demais discursos, os sujeitos da investigação não evidenciaram consideração à observação como fator determinante para a validação de teorias. 


\section{COMPREENSÃO EIDÉTICA DAS CONVERGÊNCIAS NA QUARTA CATEGORIA: IMPORTÂNCIA DO CONTEXTO HISTÓRICO E SOCIAL}

A relevância do contexto histórico e social no desenvolvimento da Cosmologia, enquanto ciência, é amplamente explanada pelo sujeito 1 nesta categoria. Ele considera que estes contextos exercem influência, direta ou indiretamente, no modo em que o cientista vai guiar os seus estudos e fazer suas postulações, pois

\section{[...] é essencial compreender a ciência como um corpo de conhecimento historicamente em expansão e que uma teoria só pode ser adequadamente avaliada se for prestada a devida atenção ao seu contexto histórico. A avaliação da teoria está intimamente ligada às circunstâncias nas quais surge" (CHALMERS, 1993, p. 60).}

Vale ressaltar, no entanto, que os demais discursos não atribuem consideração significativa aos aspectos históricos e sociais, o que pode corroborar para a possibilidade dos mesmos apresentarem visões deformadas da ciência.

\section{COMPREENSÃO EIDÉTICA DAS CONVERGÊNCIAS NA QUINTA CATEGORIA: A IMPORTÂNCIA DE FAZER SUPOSIÇÕES NO CAMPO DA COSMOLOGIA}

Ao estudar o universo, percebe-se que a comunidade científica tem informações que correspondem a porções ínfimas do mesmo e, portanto, é necessário e essencial que sejam feitas suposições de entidades desconhecidas, bem como sejam propostos experimentos puramente teóricos na tentativa de buscar explicações que satisfaçam as observações e inquietações da sociedade.

A componente imaginativa constantemente permeou o pensamento dos cientistas e proporcionou que muitos avanços fossem alcançados no desenvolvimento da Cosmologia, uma vez que "as teorias podem ser, e geralmente são, concebidas antes de serem feitas as observações necessárias para testá-las" (CHALMERS, 1993, p. 5960).

\section{COMPREENSÃO EIDÉTICA DAS CONVERGÊNCIAS NA SEXTA CATEGORIA: COSMOLOGIA COMO ÁREA DE INTEGRAÇÃO}

A Cosmologia carece da contribuição das distintas áreas do conhecimento, todavia tal concepção somente está presente no discurso do sujeito 1 , os demais interlocutores não estabeleceram relação entre ela e as diferentes áreas de estudo e 
pesquisa. Segundo, Ostermann e Cavalcanti (2011, p.7) "uma crítica ainda válida atualmente à comunidade científica, na qual grande parte dos cientistas trabalha em nichos restritos de conhecimento e poucos sequer buscam tomar conhecimento do histórico, filosófico e cultural da Ciência". Desse modo, percebe-se que a Cosmologia apenas desenvolve-se em conjunto com todo o contexto que a cerca.

\section{COMPREENSÃO EIDÉTICA DAS CONVERGÊNCIAS NA SÉTIMA CATEGORIA: TEORIA DO BIG BANG (ESTRONDÃO) E OS SEUS PILARES TEÓRICOS E/OU EXPERIMENTAIS}

Nesta categoria os sujeitos de pesquisa versam sobre suas concepções a respeito da teoria do big bang (estrondão), bem como sobre os pilares que, com efeito, consideram que, fornecem bases sólidas e confiáveis para fazer com que tal modelo cosmológico permaneça sendo o mais aceito e difundido em meio à comunidade científica.

A união entre a teoria da relatividade geral, proposta por Einstein, e as evidências observacionais (redshifts e a radiação cósmica de fundo) parecem contribuir significativamente para a consolidação do modelo cosmológico padrão, uma vez que, “embasado em todas as 'evidências' experimentais e nas 'confirmações experimentais' de 'previsões' teóricas, o big bang (estrondão) elevou-se à condição de paradigma da Cosmologia Moderna" (NEVES, 2000b p.192a). No entanto, tal teoria apresenta muitas incongruências, as quais necessitam que sejam olhadas e analisadas a luz de visões alternativas ao paradigma vigente.

\section{COMPREENSÃO EIDÉTICA DAS CONVERGÊNCIAS NA OITAVA CATEGORIA: DÚVIDAS DO SUJEITO SOBRE O MODELO COSMOLÓGICO PADRÃO}

As dúvidas e indagações referentes à origem do universo intrigam o pensamento dos interlocutores. Percebe-se que a ideia de que tudo o que se conhece surgiu a partir de uma singularidade inicial não os convence, pois, esta premissa pode sugerir que o universo é o resultado de uma criação divina, que permitiu que tudo fosse, instantaneamente, criado.

Para os demais sujeitos, parece que tais inquietações são elucidadas e, portanto, não necessitam serem discutida, ou então, podem ser consideradas irrelevantes, uma vez que, dificilmente o homem terá informações confiáveis e incontestáveis sobre a origem do universo. 


\section{COMPREENSÃO EIDÉTICA DAS CONVERGÊNCIAS NA NONA CATEGORIA: ENSINO DA COSMOLOGIA}

Nesta categoria, a maioria dos sujeitos converge suas concepções acerca da importância do ensino da Cosmologia nos diferentes níveis de ensino. Eles consideram fundamental que os estudantes compreendam, ainda que minimamente, o universo que os cercam, a partir de fenômenos que estão rotineiramente presentes em suas vidas. Contudo, é preciso que seja dado ênfase não somente para aos aspectos conteúdistas, mas também aos relacionados à história e filosofia da Ciência.

\section{COMPREENSÃO EIDÉTICA DAS CONVERGÊNCIAS NA DÉCIMA CATEGORIA}

Ao serem questionados sobre "O que é Cosmologia para você?", alguns interlocutores demostraram insegurança e até mesmo receio ao tecer suas considerações sobre o assunto. Tais sentimentos podem ser reflexos do fato que o conhecimento científico inerente à Cosmologia está em constante construção e reelaboração e, devido a isso, não se pode ter conclusões definitivas. Todavia, é possível que esta hesitação tenha implicações negativas no ensino, uma vez que, os professores, por medo de cometerem equívocos conceituais, optem por não abordarem tópicos relacionados à Cosmologia Contemporânea.

\section{COMPREENSÃO NOMOTÉTICA IMEDIATA DAS SITUAÇÕES RELATADAS PELOS SEIS SUJEITOS DE PESQUISA}

Ao trilhar o caminho da redução fenomenológica, adotado para compreender o discurso dos professores/investigadores, muitos pontos de convergência emergiram diante do questionamento inicial "O que é a Cosmologia para você?”.

As convergências desvelam que a Cosmologia é entendida como uma ciência que se destina ao estudo do universo, desde a seu suposto surgimento até a sua possível evolução. E a teoria que norteia as concepções dos sujeitos corresponde ao big bang (estrondão), uma vez que, os mesmos consideram que esta dispõe de evidências observacionais, bem como de princípios teóricos suficientes para a sua consolidação, enquanto paradigma vigente.

Em contrapartida é possível depreender que os interlocutores, apesar de, defenderem claramente o modelo cosmológico padrão, concebem que em relação ao 
estudo do universo, há muito a ser descoberto, investigado, reformulado e até mesmo refutado, uma vez que, o ser humano desconhece completamente $96 \%$ do conteúdo do universo e devido a isso, ainda está a supor a existência de entidades não detectadas e/ou observadas. Diante dessa concepção, é compreensível que os discursos apreendem dúvidas sobre determinados aspectos da teoria do big bang (estrondão), no entanto, tais impasses, sejam eles conceituais ou observacionais, não se caracterizam como um retrocesso, mas pelo contrário, configuram-se como necessários para o progresso da Cosmologia, enquanto ciência.

Em relação ao ensino da Cosmologia contemporânea, com exceção de um sujeito, os demais interlocutores da pesquisa, conferiram importância a sua abordagem, nos diferentes níveis de ensino, seja dando ênfase aos aspectos conteúdistas, no ensino da Química ou da Física, ou seja, evidenciando a relevância de discutir assuntos relacionados à Cosmologia sob o enfoque da epistemologia, para a formação de estudantes críticos e participativos. E, para alcançar tais objetivos, caminhos metodológicos foram apontados, na tentativa de salientar que, não obstante a sua complexidade, é possível e essencial que a Cosmologia esteja efetivamente presente no ambiente escolar e acadêmico.

\section{COMPREENSÃO NOMOTÉTICA GERAL}

Ao debruçar-se sob as categorias que emergiram dos discursos dos sujeitos de pesquisa, percebe-se que há muitas lacunas que podem revelar concepções que estão nas entrelinhas das falas dos interlocutores. No que se refere a segunda e terceira categoria, "Cosmologia como ciência" e "Importância dos resultados observacionais", respectivamente, somente dois sujeitos evidenciaram conceber o conhecimento científico como sendo guiado por paradigmas que exercem influências tanto na observação, quanto na interpretação de fatos e fenômenos. No "não dito" dos demais discursos, pode estar presente a concepção de que a Cosmologia é uma área de estudo resultado de um "método científico", cujas etapas são rígidas, neutras e confiáveis.

$\mathrm{Na}$ quarta categoria, "Importância do contexto histórico e social" é possível pressupor que os sujeitos não atribuem muita relevância ao fato de que o desenvolvimento da Cosmologia está relacionado aos aspectos sociais, políticos, religiosos e históricos que refletem os interesses dos cientistas em determinado contexto. A partir das lacunas existentes na quinta e sexta categoria, respectivamente "A importância de fazer suposições no campo da Cosmologia" e "Cosmologia como área 
de integração" também é presumível que os interlocutores não levam em consideração a necessidade que a Cosmologia tem em fazer suposições teóricas, na busca de compreender o que é ou não observado, bem como em buscar o conhecimento de outras áreas, na tentativa de construir um cenário universal.

As lacunas presentes na oitava categoria "Dúvidas do sujeito sobre o modelo cosmológico padrão" pode demonstrar que os sujeitos de pesquisa estão embasados em "certezas observacionais e conceituais" que são facilmente encontradas em livros de divulgação científica e na bibliografia em geral e que, portanto, não são passíveis de dúvidas e questionamentos. Todavia, a Cosmologia, enquanto ciência, é um empreendimento humano, que admite interpretações equivocadas, mudanças e reformulações no decorrer do seu desenvolvimento.

\section{CONSIDERAÇÕES FINAIS}

Um dos principais objetivos da educação, desde o ensino fundamental até a pósgraduação consiste em contribuir efetivamente para a formação de estudantes críticos e reflexivos, que consigam ir além da memorização de teorias, conceitos, datas, equações, etc. É necessário, portanto, que eles compreendam a ciência como fruto de uma construção humana não linear, bem como, tenham argumentos para opinar, discutir e tomar decisões, quando forem expostos a questões polêmicas e controvérsias.

Nessa perspectiva, percebe-se que o papel desempenhado pelo professor pode fomentar o senso crítico e reflexivo dos alunos, tanto do ponto de vista científico, como epistemológico. Todavia, quando se refere ao ensino da Cosmologia os professores e os pesquisadores, sujeitos de pesquisa, de ambas as instituiçõos de ensino superior apresentam concepções distintas. A maioria dos professores e pesquisadores considera viável e relevante o ensino da Cosmologia contemporânea nos diferentes níveis, seja, por meio de uma abordagem adequada, que contemple conceitos e conteúdos referentes ao universo em que o homem habita, ou seja, através da compreensão de fenômenos presentes no cotidiano dos estudantes, que possam estabelecer relações com o universo em larga escala. Alguns sujeitos de pesquisa foram além da perspectiva conteúdista e consideraram essencial discutir aspectos da natureza da ciência, por meio do ensino da Cosmologia contemporânea. Há, contudo, um sujeito de pesquisa que concebe, conforme sua concepção, a Cosmologia com um tema abrangente e complexo, que não está embasado em resultados conclusivos e definitivos e, portanto, não necessita ser discutido no âmbito escolar e acadêmico. 
Percebe-se assim, que a importância do ensino da Cosmologia ainda não é consenso entre os professores e pesquisadores, bem como a metodologia a ser adotada. Em relação à abordagem de modelos cosmológicos alternativos ao modelo padrão, os sujeitos de pesquisa, também não estão em consonância, pois, alguns defendem que a teoria do big bang (estrondão) apresenta dados observacionais e experimentais suficientes para consagrá-la a ponto de desconsiderar a existência das demais teorias que fornecem explicações, por vezes, mais satisfatórias. Contudo, há opiniões que divergem desta, uma vez que, alguns sujeitos de pesquisa comparam a Cosmologia a um edifício, que está sujeito a desmoronamento a qualquer novo dado observacional e experimental, ou seja, é uma ciência que ainda está em construção sob a influência do contexto histórico e social e, portanto, pode sofrer modificações e refutações, que, com efeito, podem fazer com que o paradigma vigente seja destituído. Ademais, parece ser unanimidade entre os sujeitos de pesquisa a concepção de que em relação ao universo, há muito a ser descoberto, investigado e estudado, uma vez que, se conhece apenas uma porção ínfima do mesmo.

Em relação às três evidências empíricas, redshifts, quasares e radiação cósmica de fundo, os sujeitos de pesquisa que versaram sobre as mesmas, apresentaram somente as interpretações que corroboram para a solidificação da teoria do big bang (estrondão). As dissonâncias existentes entre tais evidências, bem como, a contribuição de renomados astrônomos como, por exemplo, Halton Arp, não foram salientadas nos discursos.

Conclui-se, portanto, que a teoria do big bang (estrondão) é a mais difundida e a mais aceita em âmbito acadêmico. Esta quase certeza num fiat lux cosmológico acaba por igualar a crença dessa ciência numa certeza semelhante aos dogmas religiosos. Não há, pois, lugar para as incertezas. Contudo, não há uma resposta definitiva para melhor explicar a origem do universo, uma vez que, ao discutir-se aspectos da natureza da ciência, percebe-se que o conhecimento científico não se encontra pronto e acabado, baseado em certezas absolutas, mas sim constitui-se de constantes evoluções e reconstruções.

Com o avanço das tecnologias que permitem dados observacionais mais confiáveis, os desenvolvimentos dos estudos cosmológicos adquiriram prestígio e passaram a serem mais divulgados em espaços de socialização do saber, tais como congressos, simpósios, livros de divulgação científica e revistas especializas na área. Entretanto, ainda assim, há inúmeras possibilidades de interpretação dos resultados 
obtidos, o que evidencia a pluralidade de teorias existentes para desvendar o surgimento do universo e o complexo processo de construção do conhecimento científico.

Nessa perspectiva é fundamental que os estudantes compreendam que a teoria do big bang (estrondão) é apenas mais uma teoria, entre as outras teorias, que procuram respostas para as questões que norteiam a humanidade desde a antiguidade até os dias de hoje - de onde viemos? para onde vamos? - e, por vezes, estas outras teorias fornecem explicações mais eloquentes as evidências observacionais e experimentais.

\section{REFERÊNCIAS}

ARP, H. O universo vermelho: cosmologia e Ciência Acadêmica. São Paulo: Perspectiva, 2001.

ASSIS, A. K. T.; NEVES, M. C. D.; SOARES. D. S. L. A cosmologia de Hubble: de um universo finito em expansão a um universo infinito no espaço e no tempo. In: NEVES, M. C. D.; SILVA, J. A. P. (Org.). Evoluções e revoluções: o mundo em transição. Maringá: Massoni, 2008.

BICUDO, M. Fenomenologia: Confronte e Avanços. São Paulo: Cortez, 2000.

CHALMERS, A.F. O que é a ciência afinal? São Paulo: Brasiliense, 1993.

GRIBBIN, J. R. No início: antes e depois do Big bang. Rio de Janeiro: Campus, 1995.

HUSSERL, E. Meditações cartesianas: introdução a fenomenologia. São Paulo: Madras, 2001.

KRAGH, H. Cosmology and controversy: The Historical Development of Two Theories of the Universe. Princeton, Princeton University Press, 1996.

KUHN, T.S. A estrutura das revoluções científicas. 12ª ed, São Paulo: Perspectiva, 2013.

MARTINS, J; BICUDO, M.A.V. A pesquisa qualitativa em psicologia: fundamentos e recursos básicos. São Paulo: Morais, 1989.

NEVES, M.C.D. A Questão Controversa da Cosmologia Moderna: Huble e o infinitoparte 1. Caderno Catarinense de Ensino de Física, vol.17, n 2, p. 189-204,2000a.

NEVES, M.C.D. A Questão Controversa da Cosmologia Moderna: uma teoria e suas incongruências-parte 2. Caderno Catarinense de Ensino de Física, vol.17, n.2, p. 205$228,2000 \mathrm{~b}$.

NEVES, M.C.D. Do Mundo Fechado da Astronomia na Antiguidade à Cosmologia do Universo Fechado do Big bang: revistando velhos e novos dogmas da ciência astronômica. In NEVES, M.C.D (Org.) Astronomia e cosmologia: Fatos, Conjecturas e Refutações. Maringá: UEM, 2011, p. 161-217. 
OSTERMANN, F; CAVALCANTI, C.J.H. Epistemologia: implicações para o ensino de ciências. Porto Alegre: UFRGS, 2011.

PRAIA, J. CACHAPUZ, A. GIL-PÉREZ. Problema, teoria e observação em ciência: para uma reorientação epistemológica da educação em ciência. In CACHAPUZ et al (Org.) A necessária renovação no ensino de ciências. 3ª ed. São Paulo: Cortez, 2011.

SILK, J. O Big Bang: a origem do universo. Brasília: Universidade de Brasília, 1985.

SOARES, D.S.L. A tradução de Big Bang. Disponível em: < http://www.fisica.ufmg.br/ dsoares/aap/bgbg.htm. Acesso em 7 de fevereiro, 2016.

WEINBERG, S. Os três Primeiros Minutos: uma discussão moderna sobre a origem do universo. Rio de Janeiro: Guanabara Dois, 1980. 